\title{
Coautorias nas publicações brasileiras sobre medicina regenerativa: assimetrias na colaboração científica internacional
}

\author{
Brazilian co-authorships in regenerative medicine \\ inequalities in emerging countries scientific collaboration \\ publications:
}

\section{Coautorías en las publicaciones brasileñas acerca de la medicina regenerativa: asimetrías en la colaboración científica internacional}

\author{
Liliana Acero ${ }^{1, a}$ \\ lilianaacero2009@gmail.com | https://orcid.org/0000-0002-5460-3363
}

Helena Espellet Klein ${ }^{2, b}$

helenaklein@gmail.com | https://orcid.org/o000-0001-7105-096X

\footnotetext{
${ }^{1}$ Universidade Federal do Rio de Janeiro, Instituto de Economia, Programa de Pós-Graduação em Políticas Públicas, Estratégias e Desenvolvimento. Rio de Janeiro, RJ, Brasil.

${ }^{2}$ Instituto Nacional de Ciência e Tecnologia em Políticas Públicas, Estratégias e Desenvolvimento. Rio de Janeiro, RJ, Brasil.

a Doutorado em Sociologia pela University of Sussex.

b Doutorado em Administração pela Universidade Federal do Rio Grande do Sul.
}

\section{RESUMO}

A cooperação científica internacional tornou-se um fator essencial para que os países emergentes alcancem novos patamares de pesquisa, publicações e financiamento. No contexto de uma discussão analítica sobre a cooperação científica global, foram analisadas as publicações brasileiras indexadas na Web of Science e a coautoria entre pesquisadores locais e estrangeiros, com o objetivo de ilustrar as mudanças ocorridas na medicina regenerativa nas duas últimas décadas. O artigo conclui que, na última década, expandiu-se a coautoria entre autores brasileiros e destes com autores de países desenvolvidos, especialmente com aqueles dos Estados Unidos, mas também, em menor grau, com os de outros países emergentes e da América Latina. Pesquisadores brasileiros também publicaram artigos de impacto global, indicando a qualidade atingida, no país, pela pesquisa científica na área. A análise mostra que a colaboração abriu portas, no âmbito global, para a pesquisa local, mas também que as assimetrias científicas se mantiveram ao longo do tempo.

Palavras-chave: Publicações científicas; Medicina regenerativa; Colaboração internacional; Terapia celular; coautoria.

\section{ABSTRACT}

International scientific cooperation has become a key factor for emerging countries to improve research advancement, publication and funding. An analysis of local publications indexed in the Web of Science and co-authored between Brazilian researchers and non-residents was carried out, in the context of an analytical discussion on global scientific cooperation and with the aim of illustrating changes in the last two decades 
in regenerative medicine regarding this topic. The article concluded that in the last decade Brazil increased scientific co-authorships significantly domestically and with advanced country authors, especially with American authors, but also to a lesser degree with those of other emerging economies in and beyond Latin American. Local researchers have also published on their own several articles of global impact, revealing the academic quality attained in local sciences related to the area. Collaboration has undoubtedly opened doors for Brazilian regenerative medicine globally, but historical scientific inequalities remain.

Keywords: Scientific publications; Regenerative medicine; International collaboration; Cellular therapy; Co-authorship.

\section{RESUMEN}

La cooperación científica internacional se ha transformado en un factor sustancial para que los países emergentes progresen en investigación, publicación y financiación. Se desarrolló un análisis de publicaciones locales indexadas en la Web of Science y coautorías entre investigadores brasileños y extranjeros en el contexto de una reflexión sobre cooperación científica global y con el fin de ilustrar las modificaciones producidas en la medicina molecular regenerativa durante los dos últimos decenios. El artículo concluye que, en el último decenio, Brasil aumentó significativamente las coautorías domésticas y con autores de países avanzados, especialmente de los Estados Unidos, y en menor medida con aquellos de otras economías emergentes dentro y fuera de América Latina. Los investigadores locales han publicado varios artículos propios de impacto global, lo cual revela la calidad académica lograda, en Brasil, en el área. La colaboración ha abierto puertas en el mundo para la medicina regenerativa brasileña, pero las asimetrías científicas históricas persisten.

Palabras clave: Publicaciones científicas; Medicina regenerativa; Colaboración internacional; Terapia celular; Coautoría.

Contribuição dos autores:

Concepção e desenho do estudo: Liliana Acero.

Aquisição, análise ou interpretação dos dados: Helena Espellet Klein e Liliana Acero.

Redação do manuscrito: Liliana Acero.

Revisão crítica do conteúdo intelectual: Liliana Acero e Helena Espellet Klein.

Declaração de conflito de interesses: não há.

Fontes de financiamento: Programa de Pós-graduação em Políticas Públicas, Estratégias e Desenvolvimento (PPED), Instituto de Economia (IE), Universidade Federal do Rio de Janeiro (UFRJ) e Instituto Nacional de Ciência e Tecnologia em Políticas Públicas, Estratégias e Desenvolvimento (INCT/PPED).

Considerações éticas: não há.

Agradecimentos/Contribuições adicionais: Liliana Acero agradece às Prof. Maria Tereza Leopardi e Ana Celia Castro, coordenadora e vice-coordenadora do Programa de Pós-graduação em Políticas Públicas, Estratégias e Desenvolvimento (PPED), Instituto de Economia (IE), Universidade Federal do Rio de Janeiro (UFRJ), pelo apoio ao seu trabalho como professora visitante sênior estrangeira. As duas autoras agradecem ao Instituto Nacional de Ciência e Tecnologia em Políticas Públicas, Estratégias e Desenvolvimento (INCT/PPED) pela participação no Projeto de Pesquisa (INCT-PPED/IPEA) “Desmonte e Reconstrução de Políticas e Capacidades Estatais para o mundo pós-pandemia".

Histórico do artigo: submetido: 10 mar. 2021 | aceito: 25 ago. 2021 | publicado: 10 nov. 2021.

Apresentação anterior: não houve.

Licença CC BY-NC atribuição não comercial. Com essa licença é permitido acessar, baixar (download), copiar, imprimir, compartilhar, reutilizar e distribuir os artigos, desde que para uso não comercial e com a citação da fonte, conferindo os devidos créditos de autoria e menção à Reciis. Nesses casos, nenhuma permissão é necessária por parte dos autores ou dos editores. 


\section{INTRODUÇÃO}

A medicina regenerativa (MR) tem modificado práticas médicas convencionais e, no presente, passou a ser considerada uma "medicina personalizada" e a "medicina do futuro" (WEBSTER; HADDAD; WALDBY, 2011; EUROSTEMCELL, 2020). Ela foca a reparação e regeneração de células e tecidos, com a utilização de diferentes tipos de células-tronco, geralmente reproduzidas in vitro, e/ou introduz modificações genéticas no DNA (MASON; DUNNIL, 2007).

A MR tem sido acompanhada de narrativas de esperança pela aplicação de terapias celulares (TC) e genéticas para o tratamento de doenças incuráveis. Ainda assim, as altas expectativas induzidas nos 'públicos' e derivadas de avaliações excessivamente otimistas, na mídia, não foram alcançadas até hoje (MORRISON, 2012; RIP; JOLY, 2012).

Trata-se de uma área multidisciplinar e altamente conectada em âmbito internacional - abrangendo diferentes disciplinas científicas, como a engenharia de tecidos, a biologia e as ciências médicas (ZHAO; STROTMANN, 2010). Atualmente, o setor, na esfera global, se encontra no estágio de desenvolvimento e implementação de terapias, ou seja, na fase de tradução dos resultados de laboratório para a prática clínica.

Contudo, ainda não foram resolvidas de forma satisfatória questões de preocupação para a saúde coletiva, como: alguns dos riscos e incertezas científicas (WEBSTER; WYATT, 2020); o planejamento adequado de ensaios clínicos envolvendo produtos derivados de matéria viva (WEBSTER; HADDAD; WALDBY, 2011; MITTRA, 2016); e a regulação das terapias celulares e genéticas como medicamentos, procedimentos ou dispositivos (FAULKNER, 2012). Incertezas cientificas e regulatórias na MR demandam formas de regulamentação e governança inovadoras, especialmente para as colaborações nas áreas de pesquisa e publicação, que são essenciais para a evolução do trabalho inovador nas fronteiras da ciência e para o impacto dos diferentes países no cenário global.

Por um lado, a cooperação científica internacional torna-se um fator essencial para que o Brasil alcance novos patamares de pesquisa, publicações e financiamento. Por outro, apesar da dinâmica do setor estar se tornando global de forma crescente, territórios locais ainda são um lócus privilegiado de respostas institucionais a novos desafios específicos (JASANOFF, 2004). Políticas científicas, arranjos institucionais e regulação, no âmbito nacional, exercem um papel central na definição da produção brasileira voltada para a MR.

O Brasil implementou diferentes políticas a respeito das colaborações científicas internacionais, no período de 2000 a 2020. Na primeira metade do período, políticas para setores estratégicos encorajaram a colaboração cientifica doméstica (REZAIE, 2008). A Lei de Inovação (BRASIL, 2004), por exemplo, promoveu a criação de incubadoras tecnológicas em interação com institutos de pesquisa, o patenteamento e a transferência de inovações locais. Após 2010, o Brasil modificou sua estratégia e passou a apoiar a colaboração científica internacional para o desenvolvimento econômico em interação, principalmente, com os Estados Unidos da América (EUA) e a União Europeia (UE).

Este artigo descreve o papel das colaborações e das coautorias nacionais e internacionais e o impacto das publicações brasileiras no desenvolvimento da MR, no Brasil, segundo a sua qualidade acadêmica e a quantidade das suas citações. A análise empírica é contextualizada na discussão teórica sobre tendências globais nos intercâmbios científicos e as limitações, sobretudo para as economias emergentes, das métricas de publicações usualmente utilizadas para avaliar as capacidades científicas nacionais.

Sendo assim, este estudo se propõe a responder duas questões principais e interconectadas:

- Quais são as vantagens e desvantagens das colaborações científicas internacionais, em especial, para os países emergentes?

- Quais são as tendências e os impactos principais das publicações brasileiras sobre MR? 


\section{MÉTODO}

Este trabalho é parte de um esforço de pesquisa mais amplo realizado de forma intermitente, desde 2009, com o objetivo de analisar a inovação, a regulação e a governança em matéria de MR, no Brasil, tendo o Reino Unido (RU) - um líder global na área - como parâmetro de referência (consultar, por exemplo, Acero, 2011, 2019, e Acero e Klein, 2013). O presente artigo analisa a capacidade científica local de atuar em MR, apresentando uma abordagem quantitativa longitudinal e qualitativa baseada em dados estatísticos e qualitativos de diferentes plataformas de periódicos e publicações e, também, em informações primárias obtidas em 18 entrevistas semiestruturadas realizadas com líderes brasileiros em MR.

Dados sobre colaborações científicas, publicações e coautoria obtidos de fontes relevantes nacionais e internacionais foram analisados. Os relatórios oficiais publicamente disponíveis foram coletados nos arquivos de diferentes agências governamentais brasileiras e outros dados secundários foram obtidos em arquivos institucionais, sites e notas de organizações científicas à imprensa. A plataforma de periódicos indexados Web of Science (WoS) da Thomson Reuters - que também inclui dados dos periódicos de acesso aberto da plataforma Brazilian Scientific Electronic Library Online (Scielo) - foi utilizada como fonte de dados sobre as publicações brasileiras indexadas internacionalmente.

Além do índice mais frequentemente utilizado - o Science Citation Index Expanded (SCI-EXPANDED) - outros índices foram incluídos na busca, na Coleção Principal da WoS; são eles: Social Sciences Citation Index (SSCI), Arts \& Humanities Citation Index (A\&HCI), Conference Proceedings Citation Index - Science (CPCI-S), Conference Proceedings Citation Index - Social Science \& Humanities (CPCI-SSH) e Emerging Sources Citation Index (ESCI). Finalmente, utilizaram-se as seguintes ferramentas da WoS: o índice de citações, a classificação das áreas científicas e a seleção e ranking de países envolvidos nas publicações.

As publicações foram selecionadas, na WoS, por meio da utilização dos seguintes parâmetros de busca: a inclusão no campo 'tópico' (que inclui título, resumo e palavras-chave) de uma ou mais das seguintes expressões "stem cell"; "stem cells"; "cell therapy"; "cell therapies"; "regenerative medicine", no período entre 2000 e 20 de novembro de 2020, e a inclusão do Brasil como país de origem da afiliação institucional de um ou mais autores. As ferramentas disponibilizadas pela WoS foram usadas para a criação de rankings de instituições brasileiras, de autores brasileiros com o maior número de publicações e de países com o maior número de colaborações em artigos com autores brasileiros. Esses rankings são de elaboração própria das autoras do presente artigo. Os principais temas de pesquisa de cada autor foram consultados na Plataforma Lattes do CNPq, que registra os currículos acadêmicos dos pesquisadores no país.

\section{RESULTADOS E DISCUSSÃO}

\section{Reflexões analíticas sobre colaborações científicas}

A colaboração científica acontece no contexto de normas explícitas e tácitas - revisão por pares, incentivos e prêmios - e suas definições variam entre disciplinas e áreas (KATZ; MARTIN, 1997; SONNENWALD, 2007). Com frequência, as colaborações se iniciam informalmente nas "invisible colleges" (PRICE, 1976, p. 4), por intermédio do contato entre pesquisadores de diversas origens, assim como nos cursos de pós-graduação. Os cientistas estabelecem relações de cooperação para ganhar visibilidade, prestígio, habilidades complementares e acesso a novos recursos - questões importantes na organização social da comunidade científica. As agências de financiamento procuram avaliar o aumento da produtividade científica dentro do princípio do 'publish or perish', um incentivo fundamental à cooperação científica. Além disso, entre os autores mais prolíficos tende a haver uma grande propensão à colaboração(KRETSCHMER; LIMING; KUNDRA, 2001). 
Entre os benefícios associados à colaboração científica, podem ser salientadas a transferência de conhecimento e a ampla disseminação dos achados científicos. Por exemplo, artigos publicados em coautoria são mais citados do que aqueles com um único autor (LETA; CHAIMOVICH, 2002). É atribuída maior credibilidade científica às publicações com um grande número de autores ou instituições, e a quantidade de artigos com essa característica tem crescido recentemente (PERSSON; GLÄNZEL; DANELL, 2004, 2016).

A colaboração envolve um ethos de reciprocidade, mas isso não resulta na ausência de competição (ATKINSON; BATCHELOR; PARSONS, 1998). A cooperação tem riscos intrínsecos, que dependem fortemente da definição de regras na governança das pesquisas (ANKRAH; AL-TABBAA, 2015). Como se observa em muitos contextos científicos, existem chances de falta de reciprocidade entre autores e ainda de ética profissional, envolvendo, em alguns casos, assimetrias relacionadas ao compartilhamento de ideias e de dados, omissões na autoria e direitos de propriedade intelectual (GRUBB; EASTERBROOK, 2011).

A ciência moderna tende a ter um perfil colaborativo. Mas, ele, muitas vezes, se estabelece com base em características atribuídas à ciência pós-colonial, como: a universalização e normalização de valores e práticas ocidentais e o incentivo ao triunfalismo acadêmico de cunho europeu (HARDING, 2011). Esse tipo de desenvolvimento científico pós-colonial resultou na subjugação e na invalidação do conhecimento autóctone dos povos originários e de outros setores sociais locais (DAHDOUH-GUEBAS et al., 2003; ANDERSON; ADAMS, 2008). No que se refere às publicações, estabeleceu-se um "círculo fechado e desigual” (p. 15) na reprodução social da estrutura de colaboração científica, como descreveu Bourdieu (1992), no qual a assimetria entre a produção de autores dos países avançados e dos países emergentes tende a prevalecer.

Contudo, a cooperação internacional científica e técnica se tornou um fator essencial para o avanço da pesquisa, publicações e financiamento nos países emergentes (VELHO, 2011). Estudos de autores como Confraria e Godinho (2014) e Confraria, Godinho e Wang (2017) comprovam que criar parcerias internacionais perenes é uma forma de aumentar o impacto global dos resultados das pesquisas dos países emergentes. Como parte da reprodução das desigualdades científicas, a cooperação internacional pode também influenciar substancialmente a forma como a ciência, a política e as práticas científicas latinoamericanas são construídas e implementadas (KREIMER, 2019).

Na MR brasileira, a cooperação pode ser, em geral, caracterizada como baseada em um "modelo dependente de recursos" (resource dependant) (HALLONSTEN, 2014, p. 6), ou seja, associada à coautoria com parceiros estrangeiros, cofinanciamento internacional de ensaios clínicos e importação de insumos materiais (INCT - REGENERA, 2020). Embora a colaboração na área de MR seja considerada nas políticas públicas como uma oportunidade para melhorar a competitividade do Brasil (ACERO, 2011), podem ser identificadas assimetrias de poder entre atores nacionais e internacionais e um reconhecimento limitado das formas híbridas de produção e/ou adaptação do conhecimento ao contexto local.

Atualmente, a colaboração científica internacional está em franca expansão no que se refere às publicações relativas aos resultados das pesquisas voltadas para a MR e dos ensaios clínicos multicêntricos (ZORZANELLI et al., 2016; SANTIN; NUNEZ; MOURA, 2015). Mas, ainda é necessário melhorar, na escala global, os instrumentos de política que pretendem alcançar uma maior equidade nessa colaboração (KAYE et al., 2018), assim como criar indicadores qualitativos e quantitativos mais adequados e que ampliem o escopo do que pode ser considerado e medido como cooperação científica.

Em parte da literatura que usa a abordagem bibliométrica, a colaboração científica tem sido equivocadamente equiparada à coautoria (VANZ; STUMPF, 2010). Esse indicador é amplamente usado para medir as colaborações de pesquisa entre pessoas, instituições, países e redes de pesquisa (por exemplo, Lima, 2011, e Maia e Caregnato, 2011). Contudo, a coautoria é apenas uma faceta dos intercâmbios de pesquisa, sendo que alguns deles não têm a coautoria como resultado. 
Além disso, os indivíduos listados nas publicações nem sempre são responsáveis pelo trabalho intelectual. Tornou-se uma prática comum incluir um número crescente de "coautores honorários" em cada artigo, uma síndrome chamada de "hiper-autoria” (CRONIN, 2001, p. 559). Por exemplo, Machado (2021), no seu estudo acerca de artigos brasileiros sobre células-tronco, mostra que uma proporção significativa de artigos publicados entre 2001 e 2019 apresenta mais de 20 autores, mas alguns chegam a indicar mais de 100. Além disso, as publicações indexadas nas bases de dados mais consultadas não refletem todo o universo de artigos publicados em uma área do saber, já que as plataformas possuem suas próprias políticas de indexação (PACKER, 2014).

De modo semelhante, existem vieses nos estudos de cooperação científica baseados em análise relacional e de redes (por exemplo, Wasserman e Faust, 1994). Esses trabalhos medem a densidade das interações de grupos de atores científicos e o papel relacional dos agentes intermediários (GRÁCIO, 2018), mas, geralmente, assumem que a colaboração é um processo de interação bidirecional e equilibrado.

As formas de cooperação devem ser analisadas também qualitativamente, pois a característica dominante da colaboração entre autores de diferentes países pode ser de desequilíbrio e/ou subordinação (GONZÁLEZALCAIDE et al., 2017). Por exemplo, Smith e outros (2014) argumentam que, na elaboração de relatórios de pesquisa, uma maior parcela de tarefas técnicas e de menor responsabilidade é reservada para autores de países emergentes. Esse processo faz com que suas contribuições recebam menos reconhecimento. Rorha (2011) relaciona esse fato às diferenças de qualidade no uso da língua inglesa entre autores e ao favorecimento de colegas ocidentais próximos das editoras proeminentes como revisores dos textos. Ou, ainda, ao fato de que muitos artigos podem ser fruto de colaborações multicêntricas ou entre regiões, nas quais se mascara a escassa liderança dos autores de países emergentes.

Estudos em ciência, tecnologia e sociedade (CTS) (JASANOFF, 2004; DAGNINO, 2014) denunciaram os vieses inerentes ao uso de indicadores bibliométricos como um método privilegiado de descrição de tendências na colaboração científica. Em primeiro lugar, questionam-se os pressupostos metodológicos que resultam na tendência a limitar a análise de coautoria aos artigos que listam endereços em dois ou mais países. Em segundo lugar, a representatividade das descobertas é criticada, porque os indicadores privilegiam apenas uma forma de comunicação da ciência (MANTEN, 1980). Numa perspectiva mais aprofundada, as medições 'objetivas' da produção científica seguem critérios fechados pertencentes a certas disciplinas e a validade das próprias regras científicas raramente é discutida (DAVYT; VELHO, 2000). Sem subestimar sua relevância para o mapeamento e a validação quantitativa, os achados desses estudos devem ser contextualizados em relação à dinâmica de produção do conhecimento no campo/país de referência, assim como ao papel desempenhado por cada disciplina ou país na divisão assimétrica do trabalho científico global (RODRIGUEZ-MEDINA et al., 2019).

Nesse sentido, os periódicos internacionais cadastrados na plataforma WoS, priorizados pelas abordagens discutidas, apresentam um viés favorável aos países de liderança científica e, em especial, aos Estados Unidos (RABKIN; INHABER, 1979; FRAME, 1980; TARGINO; GARCIA, 2000). Um grande número de periódicos sobre temas de interesse dos Estados Unidos é indexado nessa plataforma. Além disso, periódicos que publicam uma coleção maior de artigos sobre um determinado tema tendem a reivindicar qualidade supostamente superior (MACHADO; VARGAS-QUESADA; LETA, 2015). Essa situação de desigualdade contribui para diminuir a visibilidade e a reputação global dos autores dos países emergentes.

Desconhecer a necessidade de reflexão crítica no uso da base de dados mencionada resulta na internacionalização da ciência 'mainstream', seguindo parâmetros estabelecidos nos países ocidentais e minimizando os saberes autóctones. Singh (2006), por exemplo, verificou taxas de aceitação mais baixas de manuscritos de autores de países emergentes em periódicos indexados. Por sua vez, Fradkin (2017) se 
refere ao fenômeno negativo da "ciência perdida" (p. 2), que se torna inacessível para muitos membros da comunidade científica global devido às incompatibilidades de estruturas e linguagens.

Como resultado da recente expansão das redes científicas, um grupo de apenas quatorze países ocupou o 'núcleo' científico global e tornou-se seletivo na escolha de novos parceiros (LEYDESDORFF; WAGNER, 2008). Embora tenha havido esforços significativos para registrar periódicos locais de países emergentes em bases de dados indexadas, ainda são muitos os que não são indexados internacionalmente. Autores com filiação em hospitais e clínicas, em muitos países latino-americanos, por exemplo, parecem continuar a publicar, principalmente, em periódicos locais (LAO; THORSTEINSDÓTTIR; CALDERÓN-SALINAS, 2018).

As atuais iniquidades, no que se refere aos pesquisadores de países emergentes, nas publicações científicas, se refletem em uma subestimação de suas contribuições, no uso injusto de seus dados ou ideias e em menor visibilidade relacionada à ordem de autoria e designação de primeiros autores ou dos autores para correspondência. Os artigos mais citados em muitas áreas científicas são, geralmente, liderados por autores de países ocidentais, mesmo quando incluem pesquisadores de economias emergentes (GONZÁLEZ-ALCAIDE et al., 2017). Os vieses de publicação têm uma incidência significativa na estrutura global desigual da ciência, complementando outros fatores estruturais, como os desequilíbrios Norte-Sul no investimento em ciência, na alocação de diferentes tipos de recursos (por exemplo, infraestruturas e equipamentos) e nos níveis de educação formal.

A ordem de apresentação dos autores ou aquele escolhido para correspondência são indicadores importantes para analisar essas assimetrias globais na pesquisa científica (CORRÊA JUNIOR et al., 2017). Zbar e Frank (2011) mostraram que os cientistas entrevistados em seu estudo tinham, pelo menos, sete vezes mais probabilidade de considerar que o primeiro autor executou a maior parte do trabalho e escreveu o manuscrito final. $\mathrm{O}$ fato de autores de países emergentes raramente ocuparem esse lugar reforça que a posição privilegiada na lista de autores nas publicações, aumenta a visibilidade dos cientistas, melhora a avaliação acadêmica e facilita a promoção na carreira (AVULA; AVULA, 2015).

Em todas as formas de colaboração em ciência existem inúmeros problemas a serem enfrentados, como a conciliação de culturas gerenciais, regras de carreira, sistemas financeiros, agendas de trabalho das equipes e implicações comerciais de projetos de pesquisa (KLEIDERMAN et al., 2018). Essas diferenças tendem a ter maior impacto, quando a colaboração é estabelecida entre autores/instituições em países com diferentes níveis de desenvolvimento científico e econômico (CASSIOLATO; LASTRES, 2005). A análise das publicações desenvolvida neste artigo baseia-se na caracterização contextual da ciência internacional já discutida e nas especificidades da evolução da MR brasileira, considerando a importância das limitações nas bases de dados utilizadas.

\section{Publicações brasileiras em MR}

O Brasil é parte de um pequeno grupo de países (como a Coreia do Sul, a China, Cingapura e o México), cuja produção científica aumentou o correspondente a quatro vezes a média mundial nos últimos trinta anos (ALMEIDA; GUIMARÃES, 2013). No período entre 2001 e 2019, na área das pesquisas com célulastronco, de acordo com a classificação mundial relacionada ao número de publicações, o Brasil ocupou a $17^{\mathrm{a}}$ posição, enquanto os Estados Unidos e a China figuraram em primeiro e segundo lugar, respectivamente (MACHADO, 2021).

$\mathrm{Na} \mathrm{MR}$, que engloba pesquisa com células-tronco, terapias celulares e genéticas, o número total de publicações indexadas, no período de 2000 a novembro de 2020, chega a 6.270, representando 1,47\% das publicações sobre MR no mundo e uma taxa de crescimento médio anual de 33,3\%. A tendência de crescimento do número de publicações se mantém ao longo da maior parte do período, sendo especialmente 
alta entre 2004 e 2009, quando o apoio financeiro público para a MR se tornou mais substancial (ACERO, 2011) e foram feitas descobertas locais de impacto global (MENDEZ-OTERO; CARVALHO, 2012).

Os artigos foram elaborados, principalmente, em universidades públicas com importante contribuição para a MR e consideradas como instituições-chave na produção de conhecimento (GIBBONS et al., 2010). A análise dos curricula vitae dos autores mostra que o número de artigos produzidos em colaborações entre cientistas seniores e alunos de cursos de pós-graduação vem crescendo significativamente, em parte, como resultado da expansão nacional desses programas. Por exemplo, em 2011, as universidades públicas responderam por $82 \%$ dos cursos de mestrado e $90 \%$ dos doutorados (HILU; GISI, 2011).

Entre as 10 instituições mais produtivas em matéria de publicações sobre MR nas últimas duas décadas, o primeiro lugar é ocupado pela Universidade de São Paulo (USP) $(n=2.084)$, seguida pela Universidade Federal de São Paulo (Unifesp) (n=697). As publicações são originadas, principalmente, em centros de pesquisa na Região Sudeste (8 centros) e na Região Sul (2) do Brasil, que concentram as atividades de MR (PERSSON; GLÄNZEL; DANELL, 2016). Hospitais públicos e empresas privadas locais são pouco envolvidos com pesquisa e publicam muito menos. São exceções as poucas empresas spin-offs de sucesso - como a Hygeia da Universidade Federal do Rio de Janeiro (UFRJ), a Pluricell Biotech da USP e a Eva Scientific da Universidade Estadual de Campinas (Unicamp) - bem como duas empresas que armazenam sangue do cordão umbilical e da placenta - Cryopraxis e CordVida (ACERO, 2019).

Autores prolíficos, em geral aqueles com mais de dez artigos publicados, tendem a ser afiliados a centros de pesquisa privados e a trabalhar com doenças do sangue e transplantes, temas de tradição científica local, desde o final dos anos 1950. Segundo os entrevistados na pesquisa, a maioria dos autores publicou entre um e dois artigos no período em estudo e, comumente, junto com alunos de pós-graduação.

Os autores brasileiros dão prioridade à publicação em periódicos estrangeiros (MUELLER, 2005). Souza (2017) argumenta que muitos periódicos nacionais indexados também procuram publicar em inglês para dar maior visibilidade à pesquisa local. Cinco periódicos indexados, de acordo com os entrevistados, prevalecem nas escolhas dos cientistas brasileiros que trabalham com MR: Plos One, Scientific Reports, Stem Cell Research \& Therapy, Brazilian Journal of Medical and Biological Research (um periódico nacional publicado em inglês) e Biology of Blood and Marrow Transplantation. Os principais temas da pesquisa local vêm se modificando. Tendo se concentrado, inicialmente, na hematologia, na última década, eles vêm discutindo cada vez mais a biologia celular, ou seja, o estudo dos mecanismos biológicos das células para a especialização induzida (MACHADO; VARGAS-QUESADA; LETA, 2015) - 'hot topic' que também tem dominado a literatura internacional (LI et al., 2009).

\section{Motivações para publicar artigos em coautoria}

Os artigos com apenas autores brasileiros representaram quase $61 \%$ de todas as publicações, no período em estudo ( $n=3.870$ ). Desde 2015, a colaboração internacional em publicações aumentou, significativamente, atingindo mais da metade do total de artigos publicados em $2020(n=296)$, em virtude, principalmente, do recente incentivo governamental à cooperação científica internacional.

Autores de uma centena de países diferentes colaboraram em publicações com autores brasileiros, nas últimas duas décadas. Porém, é importante notar que quase 21\% dessas publicações foram produzidas em colaborações entre brasileiros e, pelo menos, um residente nos Estados Unidos ( $\mathrm{n}=1.354$ artigos) (Tabela 1). Sugere-se que esse alto percentual está relacionado ao fato de que as instituições brasileiras estabeleceram diversos acordos de treinamento e pesquisa com centros de pesquisa norte-americanos, como o California Institute of Regenerative Medicine, o Harvard Stem Cell Institute (HSCI), o Center for Regenerative Medicine e a Mayo Clinic. 


\section{Tabela 1-10 principais países de origem dos cientistas que publicaram artigos em coautoria com} brasileiros (2000-20/11/2020)

\begin{tabular}{clcc} 
Posição & País* & Publicações & $\mathbf{( \% ) * *}$ \\
$1^{0}$ & Estados Unidos & 1354 & 21,60 \\
$2^{\circ}$ & Inglaterra & 344 & 5,49 \\
$3^{\circ}$ & Alemanha & 320 & 5,10 \\
$4^{\circ}$ & Itália & 304 & 4,85 \\
$5^{\circ}$ & França & 301 & 4,80 \\
$6^{\circ}$ & Canadá & 229 & 3,65 \\
70 & Espanha & 193 & 3,08 \\
$8^{\circ}$ & Holanda & 166 & 2,65 \\
$9^{\circ}$ & Japão & 140 & 2,23 \\
$10^{\circ}$ & Austrália & 139 & 2,22 \\
\hline
\end{tabular}

Notas: *Significa que, em todas as publicações em que há, ao menos, um autor com endereço no Brasil, há também, ao menos, um autor de cada um desses países. Cada país é contado uma vez por publicação.

** O percentual se refere ao total de publicações (6.270) em que há ao menos um autor com endereço no Brasil. Fonte: elaboração das autoras com base nos dados da WoS.

Dentre os demais países de origem dos colaboradores, predominam os de liderança global em MR, como Inglaterra, Alemanha, Itália, França e Canadá - variando entre 350 e aproximadamente 300 artigos por país. No caso da Europa, as colaborações científicas são promovidas pelas redes de pesquisa financiadas pelos Programas de Pesquisa da Comissão Europeia. Dados das entrevistas realizadas mostram que a instituição inglesa que mais colaborou com pesquisadores brasileiros foi o Kings College London ( $\mathrm{n}=12)$. Por sua vez, o Canadá desenvolveu um interesse na expansão internacional da MR e apareceu como país de origem de coautores de 209 artigos (MCMAHON et al. 2010). A Alemanha teve um papel pioneiro no estudo das cardiopatias (WILSON-KOVACS; WEBER; HAUSKELLER, 2010), que é também relevante nas prioridades de pesquisa brasileiras. Dentro da rede de colaboração, os autores dos Estados Unidos e da Europa tendem a ocupar as posições dominantes na ordem dos autores, seja como primeiro autor ou autor para correspondência.

As coautorias com os países conhecidos como Brics - um grupo de países emergentes, que inclui Brasil, China, Índia, Rússia e África do Sul - se iniciaram em 2007. O desenvolvimento desses países baseia-se em grande medida no aumento de seus investimentos em pesquisa e desenvolvimento (P\&D). No entanto, o número total de publicações com autores dos países que constituem o Brics, no período analisado, foi menor ( $n=202)$ do que com os pesquisadores de países avançados. Entre o grupo dos que compõem o Brics, a coautoria com autores da China predominou $(\mathrm{n}=86)$, enquanto as coautorias com autores da Índia ( $\mathrm{n}=$ 49) e da Rússia $(n=46)$ ocuparam as posições subsequentes. Os parceiros sul-africanos colaboraram em menos de um quarto do total de artigos publicados.

Ainda assim, os pesquisadores brasileiros entrevistados expressaram certas reservas para estabelecer parcerias com a China, devido às incertezas de seus padrões regulatórios (ACERO, 2019). Entre os demais países do grupo, apenas a Índia apresentou um desenvolvimento substantivo na área de MR (SALTER, 2008). Além disso, uma maior cooperação com a África do Sul, em especial no que diz respeito a transplantes de medula óssea e sangue de cordão umbilical, se mostra viável, uma vez que essas pesquisas já estão bem estabelecidas em ambos os países (CHIMA, 2013).

O Brasil, na qualidade de líder regional em matéria de MR, colaborou em publicações com 23 países da América Latina, desde 2003, mas de forma mais significativa, apenas a partir de 2011. São mais 
relevantes as colaborações com a Argentina (n=69), país que possui pesquisadores altamente qualificados em pesquisa básica e pré-clínica, mas carece da infraestrutura, dos equipamentos e das capacidades de engenharia de tecidos do Brasil (BORTZ; ROSEMANN; VASEN, 2019). Além disso, em 2009, o Ministério da Saúde e a Rede Nacional de Terapia Celular (RNCT) estabeleceram o Programa Binacional de Terapia Celular (Probiotec) para apoiar a pesquisa, o desenvolvimento tecnológico e a capacitação, que continua em andamento e tem apresentado resultados muito positivos.

Na segunda posição entre os países da América Latina, foram publicados 44 artigos em parceria envolvendo brasileiros e chilenos. O Chile desenvolveu, principalmente, capacidades em pesquisa préclínica e modelagem de doenças humanas. Mas também está realizando, gradualmente, ensaios clínicos de fase I com células-tronco adultas no transplante de medula óssea para doenças malignas do sangue. No entanto, ainda carece de regulamentação adequada para a MR (CONICYT, 2013).

Uruguai, México e Colômbia também interagiram em publicações com pesquisadores brasileiros, contudo em números inferiores, mas semelhantes entre eles. Apenas mais recentemente, os três países começaram um desenvolvimento substantivo da MR, ainda que a tivessem definido como prioridade nacional de pesquisa tempos atrás (PALMA et al., 2015). O Uruguai publicou 1\% dos artigos sobre célulastronco, entre 2010-2013, e tem experiência significativa em transplante de células-tronco, nas propriedades das células mesenquimais e nos efeitos de terapias na doença de Parkinson (ÁLVAREZ, 2009). Embora a regulamentação da MR tenha sido implementada nesse país, os valores médios de financiamento por projeto são reduzidos e, devido ao tamanho pequeno da população, os ensaios clínicos relevantes são escassos (ÁLVAREZ, 2009).

Desde 2014, a Sociedade Mexicana de Pesquisa em Células-Tronco tem promovido cada vez mais a área local, tendo as células-tronco hematopoiéticas, neurais, embrionárias, mesenquimais e cancerosas como seus interesses principais. No entanto, a regulamentação resulta aquém dos padrões internacionais para a MR clínica, uma situação que expõe os pacientes a riscos desnecessários (MEDINA-ARELLANO, 2012).

Uma quantidade bem menor de trabalhos acadêmicos colombianos, sobre MR, foram publicados no período de estudo, embora sites de hospitais locais mostrem pesquisas em andamento sobre vetores virais, reprogramação celular e futuros estudos clínicos sobre doenças diversas.

As iniciativas brasileiras para a colaboração internacional mudaram, na última década. Tendo, no início dos anos 2000, priorizado as colaborações domésticas, a partir de 2015, as políticas do país se voltaram para a colaboração internacional com os principais atores globais da MR. Apesar de estabelecer, gradualmente, uma aproximação maior nas parcerias com autores dos países latino-americanos e do Brics, o Brasil manteve a predominância das colaborações com os Estados Unidos para o fortalecimento do seu desenvolvimento científico em várias áreas, incluída a MR (SOUZA, 2014).

O gráfico a seguir sintetiza a evolução dos artigos com colaborações entre autores brasileiros e de diferentes regiões, ao longo do período analisado. 


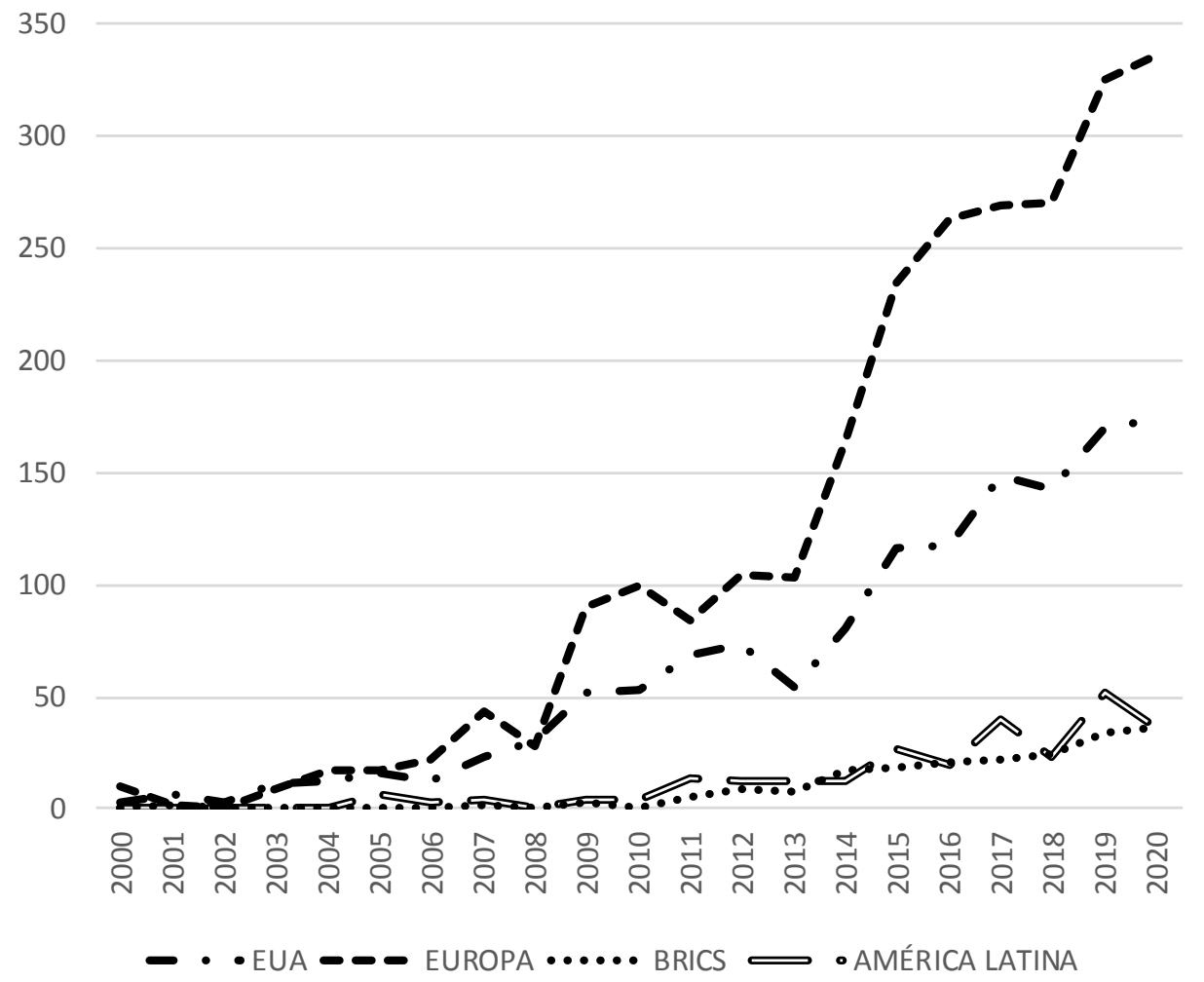

Figura 1 - Colaborações entre brasileiros e coautores estrangeiros por região, EUA e Brics (2000-20/11/2020) Fonte: elaboração das autoras com base nos dados da WoS.

\section{Impacto global}

Entre as dez publicações sobre MR mais citadas, duas delas foram produzidas exclusivamente por autores vinculados a instituições brasileiras, ocupando a $1^{\mathrm{a}}$ e a $9^{\mathrm{a}}$ posições no ranking de artigos mais citados no período analisado (Tabela 2).

Tabela 2 - As 10 publicações mais citadas publicadas em coautoria com autores brasileiros (200020/11/2020)

\begin{tabular}{cclc} 
Posição & $\begin{array}{l}\text { Ano de } \\
\text { Publicação }\end{array}$ & Países dos coautores & $\begin{array}{c}\text { Número de } \\
\text { citações }\end{array}$ \\
\hline $1^{\circ}$ & 2006 & - & 1.350 \\
$2^{\circ}$ & 2003 & Estados Unidos & 936 \\
$3^{\circ}$ & 2007 & Austrália; Áustria; Canadá; Alemanha; Estados Unidos & 851 \\
$4^{\circ}$ & 2009 & Estados Unidos & 797 \\
$5^{\circ}$ & 2015 & Áustria; Canadá; Alemanha, Japão; Espanha; Estados Unidos & 699 \\
$6^{\circ}$ & 2008 & Estados Unidos & 688 \\
$7^{\circ}$ & 2009 & Canadá; Alemanha; Noruega; Estados Unidos & 627 \\
$8^{\circ}$ & 2010 & França; Japão, Holanda; Noruega & 614 \\
$9^{\circ}$ & 2016 & - & 537 \\
$1^{\circ}$ & 2007 & Estados Unidos & 504 \\
\hline
\end{tabular}

Fonte: elaboração das autoras com base nos dados da WoS.

O artigo com mais citações ( $\mathrm{n}=1.350)$ discute a localização no corpo das células-tronco mesenquimais e foi publicado no Journal of Cell Science por autores vinculados à Universidade Federal do Rio Grande 
do Sul (UFRGS) (MEIRELLES; CHAGASTELLES; NARDI, 2006). Um estudo pioneiro sobre o zika vírus também foi produzido exclusivamente por autores brasileiros, tendo sido citado 537 vezes. O zika vírus é inoculado em humanos pelo mosquito Aedes aegypti e pode ser transmitido verticalmente durante a gravidez, causando frequentemente microcefalia em bebês (DINIZ, 2016). O artigo - que ocupa a 9ª posição entre os 10 mais citados - foi redigido por pesquisadores de um instituto de pesquisa privado, o Instituto D’OR de Pesquisa e Educação do Rio de Janeiro, e publicado na Science (GARCEZ et al., 2016).

Nos artigos com coautoria entre autores brasileiros e estrangeiros, a ordem dos nomes dos autores pode ser extremamente útil para avaliar o domínio potencial Norte-Sul entre autores e/ou a visibilidade de parceiros de carreira profissional mais recente (KIM, 2006; MENEGHINI; PACKER; NASSI-CALÒ, 2008). Dentre as 10 publicações mais citadas, cinco artigos tiveram como primeiro autor ou autor para correspondência coautor(es) americano(s), tendo ocupado as $2^{\mathrm{a}}$ (936 citações), $4^{\mathrm{a}}, 5^{\mathrm{a}}, 7^{\mathrm{a}}$ e $10^{\mathrm{a}}$ posições no ranking. Metade de todos os artigos altamente citados $(n=5)$ teve pesquisadores brasileiros como primeiros autores ou autores para correspondência, revelando uma tendência a certa simetria na publicação de artigos extremamente qualificados.

\section{CONCLUSÕES}

Os principais resultados deste trabalho mostram que, nas últimas duas décadas, o Brasil aumentou, significativamente, as coautorias científicas nacionais concernentes à MR. Pesquisadores locais também publicaram sem coautoria estrangeira dois artigos de impacto global, mostrando a qualidade acadêmica alcançada por setores da MR brasileira. Porém, na última década, devido às políticas públicas de incentivo, as coautorias cresceram, principalmente, com pesquisadores norte-americanos e europeus. Além disso, elas se expandiram de forma muito mais limitada com autores de outras economias emergentes que fazem parte da América Latina, ou não, como por exemplo, as dos países que constituem o Brics.

No Brasil, a MR já foi definida como área de prioridade estratégica nacional (ACERO, 2011). Parece haver uma série de temas de interesse mútuo entre os pesquisadores latino-americanos, que mereceria um maior enfoque. Uma expansão das parcerias, na MR, poderia contribuir para consolidar o papel de liderança do Brasil na região, bem como para atualizar a tão necessária regulamentação regional da pesquisa cooperativa e dos ensaios clínicos regionais (PALMA et al., 2015). Essas parcerias poderiam a promover estudos conjuntos sobre doenças negligenciadas (ABECASSIS et al., 2019) e doenças não transmissíveis em ascensão na América Latina (WEBBER et al., 2012). Para atingir esses objetivos, entretanto, seria necessária uma maior estabilidade na alocação de recursos para a cooperação científica regional.

Sem dúvida, a colaboração abriu portas para a MR brasileira internacionalmente, ainda que isso não tenha acontecido sem desigualdades na divisão do trabalho científico. As assimetrias, apenas na publicação de artigos muito relevantes e qualificados parecem estar se nivelando, ultimamente, como observado nos altos números de citação de artigos de autores exclusivamente brasileiros ou publicados em coautoria com autores estrangeiros. No entanto, o desenho predominantemente quantitativo deste estudo e as limitações da base de dados utilizada não nos permitem avaliar com mais profundidade as inequidades científicas. Seria necessária a realização de um trabalho substantivo de natureza qualitativa para determinar a extensão dessas desigualdades, o que indica um caminho para pesquisas futuras. À medida que as principais políticas públicas brasileiras favorecerem a interação com os colegas de países avançados, por um lado, é possível que o trabalho da MR brasileira aumente sua integração global; mas, por outro, essa integração pode vir a acontecer em posição de desvantagem para o Brasil. Como resguardo, é necessário que uma regulação mais adequada para as colaborações científicas internacionais seja elaborada e implementada, em âmbito nacional e supranacional. 
Reciis - Revista Eletrônica de Comunicação, Informação \& Inovação em Saúde, Rio de Janeiro, v. 15, n. 4, p. 987-1005, out./dez. 2021 [www.reciis.icict.fiocruz.br] e-ISSN 1981-6278

\section{REFERENCIAS}

ABECASSIS, Philippe et al. DNDi, a Distinctive Illustration of Commons in the Area of Public Health. Paris: Agence Française de Développement, 2019. (Research Paper 93). Disponível em: https://www.dndi.org/ wp-content/uploads/2019/02/CommonsAreaPublicHealth_AFDResearchPaper_2019.pdf. Acesso em: $15 \mathrm{dez}$. 2020.

ACERO, Liliana. Pesquisas e terapias com células-tronco: governança, visões sociais e o debate no Brasil. Rio de Janeiro: E-papers, 2011.

ACERO, Liliana. Regulação internacional e governança na medicina regenerativa: trajetórias do Reino Unido e a União Europeia e repercussões para a saúde coletiva global. OIKOS, Rio de Janeiro, v. 18, n. 2, p. 82-95, 2019. Disponível em: http://www.revistaoikos.org/seer/index.php/oikos/article/viewArticle/592. Acesso em: 29 set. 2021.

ACERO, Liliana; KLEIN, Helena Espellet. Ciência e colaboração científica: as publicações em pesquisa e terapia celular no Brasil. Parcerias Estratégicas, Brasília, DF, v.18, n. 37, p. 49-70, 2013. Disponível em: http://seer.cgee.org.br/index.php/parcerias_estrategicas/article/viewFile/723/663. Acesso em: 29 set. 2021.

ALMEIDA, Elenara Chaves Edler de; GUIMARÃES, Jorge Almeida. Brazil's growing production of scientific articles-how are we doing with review articles and other qualitative indicators? Scientometrics, Amsterdã, v. 97, n. 2, p. 287-315, 2013. DOI: http://dx.doi.org/10.1007/s11192-013-0967-y. Disponível em: https://link. springer.com/article/10.1007\%2Fs11192-013-0967-y. Acesso em: 29 set. 2021.

ÁLVAREZ, I. et al. Three Decades of the History of Donation and Transplantation in Uruguay. Transplantation Proceedings, Orlando, v. 41, n. 8, p. 3495-3499, 2009. DOI: http://dx.doi.org/10.1016/j. transproceed.2009.09.005. Disponível em: https://www.sciencedirect.com/science/article/abs/pii/ S0041134509012536?via\%3Dihub. Acesso em: 29 set. 2021.

ANDERSON, Warwick; ADAMS, Vincanne. Pramoedya's Chickens: postcolonial studies of technoscience. In: HACKETT, Edward J. et al. The Handbook of Science and Technology Studies. Cambridge: MIT Press, 2008. p. 181-204.

ANKRAH, Samuel; AL-TABBAA, Omar. Universities-industry collaboration: a systematic review. Scandinavian Journal of Management, [s. I.], v. 31, n. 3, p. 387-408, set. 2015. DOI: http://dx.doi. org/10.1016/j.scaman.2015.02.003. Disponível em: https://www.sciencedirect.com/science/article/abs/pii/ S0956522115000238?via\%3Dihub. Acesso em: 29 set. 2021.

ATKINSON, Paul; BATCHELOR, Claire; PARSONS, Evelyn. Trajectories of Collaboration and Competition in a Medical Discovery. Science, Technology, \& Human Values, [s. I.], v. 23, n. 3, p. 259-284, 1998. DOI: http://dx.doi.org/10.1177/016224399802300301. Disponível em: https://journals.sagepub.com/ doi/10.1177/016224399802300301. Acesso em: 29 set. 2021.

AVULA, Jayakumar; AVULA, Haritha. Authors, authorship order, the moving finger writes. Journal of Indian Society of Periodontology, [s. I.], v. 19, n. 3, p. 258-262, 2015. DOI: http://dx.doi.org/10.4103/0972124x.145782. Disponível em: https://www.jisponline.com/text.asp?2015/19/3/258/145782. Acesso em: 29 set. 2021.

BORTZ, Gabriela; ROSEMANN, Achim; VASEN, Federico. Shaping stem cell therapies in Argentina: regulation, risk management and innovation policies. Sociologias, Porto Alegre, v. 21, n. 50, p. 116-155, 2019. DOI: http:// dx.doi.org/10.1590/15174522-02105004. Disponível em: https://www.scielo.br/j/soc/a/sHsDSyJSwGjKykDfHM Rf3bp/?lang=en. Acesso em: 29 set. 2021.

BOURDIEU, Pierre. O poder simbólico. Rio de Janeiro: Bertrand Brasil, 1992.

BRASIL. Lei no 10973, de 2 de dezembro de 2004. Dispõe sobre incentivos à inovação e à pesquisa científica e tecnológica no ambiente produtivo e dá outras providências. Diário Oficial da União: seção 1, Brasília, DF, p. 2, 3 dez. 2004. Disponível em: https://www2.camara.leg.br/legin/fed/lei/2004/lei-10973-2-dezembro-2004534975-publicacaooriginal-21531-pl.html. Acesso em: 29 set. 2021.

CASSIOLATO, José Eduardo; LASTRES, Helena Maria Martins. Sistemas de inovação e desenvolvimento: as implicações de política. São Paulo em Perspectiva, São Paulo, v. 19, n. 1, p. 34-45, 2005. DOI: http://dx.doi. org/10.1590/s0102-88392005000100003. Disponível em: https://www.scielo.br/j/spp/a/9V95npkxV66Yg8vPJTp HfYh/?lang=pt. Acesso em: 29 set. 2021. 
CHIMA, Sylvester C. Global medicine: is it ethical or morally justifiable for doctors and other healthcare workers to go on strike? BMC Medical Ethics, [s. I.], v. 14, n. 1, p. 1-10, 2013. DOI: http://dx.doi.org/10.1186/14726939-14-s1-s5. Disponível em: https://bmcmedethics.biomedcentral.com/articles/10.1186/1472-6939-14-S1-S5. Acesso em: 29 set. 2021.

CONFRARIA, Hugo; GODINHO, Manuel Mira. The impact of African science: a bibliometric analysis.

Scientometrics, Amsterdã, v. 102, n. 2, p. 1241-1268, 2014. DOI: http://dx.doi.org/10.1007/s11192-014-1463-8. Disponível em: https://link.springer.com/article/10.1007\%2Fs11192-014-1463-8. Acesso em: 29 set. 2021.

CONFRARIA, Hugo; GODINHO, Manuel Mira; WANG, Lili. Determinants of citation impact: a comparative analysis of the global south versus the global north. Research Policy, Amsterdã, v. 46, n. 1, p. 265-279, 2017. DOI: http://dx.doi.org/10.1016/j.respol.2016.11.004. Disponível em: https://www.sciencedirect.com/science/ article/abs/pii/S0048733316301822?via\%3Dihub. Acesso em: 29 set. 2021.

CONICYT. Principales indicadores cienciométricos de la actividad científica chilena 2011: Informe 2013. Santiago do Chile: Altazores Ediciones, 2013. Disponível em: https://www.conicyt.cl/blog/2013/08/21/ principales-indicadores-cienciometricos-de-la-actividad-cientifica-chilena-2011-informe-2013/. Acesso em: 15 dez. 2020.

CORRÊA JUNIOR, Edilson A. et al. Patterns of authors contribution in scientific manuscripts. Journal of Infometrics, [s. I.], v. 11, n. 2, p. 498-510, 2017. DOI: http://dx.doi.org/10.1016/i.joi.2017.03.003. Disponível em: https://www.sciencedirect.com/science/article/abs/pii/S1751157716302693?via\%3Dihub. Acesso em: 29 set. 2021

CRONIN, Blaise. Hyperauthorship: a postmodern perversion or evidence of a structural shift in scholarly communication practices? Journal of The American Society for Information Science and Technology, Nova York, v. 52, n. 7, p. 558-569, 2001. DOI: http://dx.doi.org/10.1002/asi.1097. Disponível em: https:// onlinelibrary.wiley.com/doi/10.1002/asi.1097. Acesso em: 29 set. 2021.

DAGNINO, Renato. A anomalia da política de ciência e tecnologia. Revista Brasileira de Ciências Sociais, São Paulo, v. 29, n. 86, p. 45-55, 2014. DOI: http://dx.doi.org/10.1590/s0102-69092014000300004. Disponível em: https://www.scielo.br/j/rbcsoc/a/FZnTFMvDJ6ydK8srQh757wp/?lang=pt. Acesso em: 29 set. 2021.

DAHDOUH-GUEBAS, Farid et al. Neo-colonial science by the most industrialised upon the least developed countries in peer-reviewed publishing. Scientometrics, Amsterdã, v. 56, n. 3, p. 329-343, 2003. DOI: http:// dx.doi.org/10.1023/a:1022374703178. Disponível em: https://link.springer.com/article/10.1023\%2FA\% 3A1022374703178. Acesso em: 29 set. 2021.

DAVYT, Amilcar; VELHO, Léa. A avaliação da ciência e a revisão por pares: passado e presente. como será o futuro? História, Ciências, Saúde-Manguinhos, Rio de Janeiro, v. 7, n. 1, p. 93-116, 2000. DOI: http://dx.doi. org/10.1590/s0104-59702000000200005. Disponível em: https://www.scielo.br/j/hcsm/a/QYbkKSZJ4hfBnq4xD sLhDpx/?lang=pt. Acesso em: 29 set. 2021.

DINIZ, Debora. Vírus zika e mulheres. Cadernos de Saúde Pública, Rio de Janeiro, v. 32, n. 5, p. 1-4, 2016. DOI: http://dx.doi.org/10.1590/0102-311x00046316. Disponível em: https://www.scielo.br/j/csp/a/4wsWG3TkLX VMaNNTdW3JmcK/?lang=pt. Acesso em: 29 set. 2021.

EUROSTEMCELL. Regeneration: what does it mean and how does it work?. [S. I.]: EuroStemCell, c2020. Disponível em: https://www.eurostemcell.org/regeneration-what-does-it-mean-and-how-does-it-work. Acesso em: 15 ago. 2020.

FAULKNER, Alex. Commensuration and proliferation: similarity and divergence in law's shaping of medical technology. Law, Innovation and Technology, [s. I.], v. 4, n. 2, p. 165-184, 2012. DOI: http://dx.doi. org/10.5235/lit.4.2.165. Disponível em: https://www.tandfonline.com/doi/abs/10.5235/LIT.4.2.165. Acesso em: 29 set. 2021.

FRADKIN, Chris. Scientific Publication for Nonnative English Speakers: a retrospective of a workshop in Brazil. Science Communication, Thousand Oaks, v. 39, n. 3, p. 395-403, 2017. DOI: http://dx.doi.org/10.1177/1075547017710244. Disponível em: https://journals.sagepub.com/ doi/10.1177/1075547017710244. Acesso em: 29 set. 2021.

FRAME, J. D. Measuring scientific activity in lesser developed countries. Scientometrics, Amsterdã, v. 2, n. 2, p. 133-145, 1980. DOI: http://dx.doi.org/10.1007/bf02279364. Disponível em: https://link.springer.com/ article/10.1007\%2FBF02279364. Acesso em: 29 set. 2021. 
GARCEZ, Patrícia P. et al. Zika virus impairs growth in human neurospheres and brain organoids. Science, Washington, DC, v. 352, n. 6287, p. 816-818, 2016. DOI: http://dx.doi.org/10.1126/science.aaf6116. Disponível em: https://www.science.org/lookup/doi/10.1126/science.aaf6116. Acesso em: 29 set. 2021.

GIBBONS, Michael et al. The new production of knowledge: the dynamics of science and research in contemporary societies. Londres: SAGE Publications, 2010.

GONZÁLEZ-ALCAIDE, Gregorio et al. Dominance and leadership in research activities: collaboration between countries of differing human development is reflected through authorship order and designation as corresponding authors in scientific publications. Plos One, São Francisco, v. 12, n. 8, p. e0182513, 2017. DOI: http://dx.doi.org/10.1371/journal.pone.0182513. Disponível em: https://journals.plos.org/plosone/ article?id=10.1371/journal. pone.0182513. Acesso em: 29 set. 2021.

GRÁCIO, Maria Claudia Cabrini. Colaboração científica. Brazilian Journal of Information Science, Marília, v. 12, n. 2, p. 24-32, 2018. http://dx.doi.org/10.36311/1981-1640.2018.v12n2.04.p24. Disponível em: https:// revistas.marilia.unesp.br/index.php/bjis/article/view/7976. Acesso em: 29 set. 2021.

GRUBB, Alicia M.; EASTERBROOK, Steve M. On the Lack of Consensus over the Meaning of Openness: an empirical study. Plos One, São Francisco, v. 6, n. 8, p. e23420, 17 ago. 2011. DOI: http://dx.doi. org/10.1371/journal.pone.0023420. Disponível em: https://journals.plos.org/plosone/article?id=10.1371/journal. pone.0023420. Acesso em: 29 set. 2021.

HALLONSTEN, Olof. How scientists may 'benefit from the mess': a resource dependence perspective on individual organizing in contemporary science. Social Science Information, Londres, v. 53, n. 3, p. 341362, 2014. DOI : http://dx.doi.org/10.1177/0539018414524037. Disponível em: https://journals.sagepub.com/ doi/10.1177/0539018414524037. Acesso em: 29 set. 2021.

HARDING, Sandra (ed.). The postcolonial science and technology studies reader. Durham: Duke University Press, 2011.

HILU, Luciane; GISI, Maria Lourdes. Produção científica no Brasil: um comparativo entre as universidades públicas e privadas. In: CONGRESSO NACIONAL DE EDUCAÇÃO: $1^{\circ}$ SEMINÁRIO INTERNACIONAL DE REPRESENTAÇÕES SOCIAIS SUBJETIVIDADE E EDUCAÇÃO, 10., 2011, Curitiba. Anais [...]. Curitiba: X Educere, 2011. p. 5664-5672. Disponível em: https://educere.bruc.com.br/CD2011/pdf/5221_3061.pdf. Acesso em: 15 dez. 2020.

INSTITUTO NACIONAL DE CIÊNCIA E TECNOLOGIA EM MEDICINA REGENERATIVA (INCT REGENERA). Homepage do INCT - REGENERA. Rio de Janeiro: INCT - REGENERA, c2020. Disponível em: http://www.inctregenera.org.brl. Acesso em: 18 abr. 2020.

JASANOFF, Sheila (ed.). States of knowledge: the co-production of science and the social order. Milton Park: Routledge, 2004.

KATZ, J. Sylvan; MARTIN, Ben R. What is research collaboration? Research Policy, Amsterdã, v. 26, n. 1, p. 1-18, 1997. DOI: http://dx.doi.org/10.1016/s0048-7333(96)00917-1. Disponivel em: https://www.sciencedirect. com/science/article/abs/pii/S0048733396009171?via\%3Dihub. Acesso em: 29 set. 2021.

KAYE, Jane et al. Including all voices in international data-sharing governance. Human Genomics, [s. I.], v. 12, n. 1, p. 1-6, 2018. DOI: http://dx.doi.org/10.1186/s40246-018-0143-9. Disponível em: https://humgenomics. biomedcentral.com/articles/10.1186/s40246-018-0143-9. Acesso em: 29 set. 2021.

KIM, Ki-Wan. Measuring international research collaboration of peripheral countries: taking the context into consideration. Scientometrics, Amsterdã, v. 66, n. 2, p. 231-240, 2006. http://dx.doi.org/10.1007/s11192-0060017-0. Disponível em: https://link.springer.com/article/10.1007\%2Fs11192-006-0017-0. Acesso em: 29 set. 2021.

KLEIDERMAN, Erika et al. Overcoming barriers to facilitate the regulation of multi-centre regenerative medicine clinical trials. Stem Cell Research \& Therapy, [s. I.], v. 9, n. 1, p. 1-9, 8 2018. DOI: http://dx.doi.org/10.1186/ s13287-018-1055-2. Disponível em: https://www.amimedsci.org/article/S0002-9629(15)31370-7/fulltext. Acesso em: 29 set. 2021.

KREIMER, Pablo. Science and Society in Latin America: peripheral modernities. Nova York: Routledge, 2019. 
KRETSCHMER, Hildrun; LIMING, Liang; KUNDRA, Ramesh. Foundation of a Global Interdisciplinary Research Network (COLLNET) with Berlin as the Virtual Centre. Scientometrics, Amsterdã, v. 52, n. 3, p. 531-537, 2001. DOI: http://dx.doi.org/10.1023/a:1014268505676. Disponível em: https://link.springer.com/article/10.1023 \%2FA\%3A1014268505676. Acesso em: 29 set. 2021.

LAO, Dante Israel León-De; THORSTEINSDÓTTIR, Halla; CALDERÓN-SALINAS, José Víctor. The rise of health biotechnology research in Latin America: a scientometric analysis of health biotechnology production and impact in Argentina, Brazil, Chile, Colombia, Cuba and Mexico. Plos One, São Francisco, v. 13, n. 2, p. e0191267, 2018. DOI: http://dx.doi.org/10.1371/journal.pone.0191267. Disponível em: https://journals.plos.org/ plosone/article?id=10.1371/journal.pone.0191267. Acesso em: 29 set. 2021.

LETA, Jacqueline; CHAIMOVICH, Hernan. Recognition and international collaboration: the Brazilian case. Scientometrics, Amsterdã, v. 53, n. 3, p. 325-335, 2002. DOI: http://dx.doi.org/10.1023/a:1014868928349. Disponível em: https://link.springer.com/article/10.1023\%2FA\%3A1014868928349. Acesso em: 29 set. 2021.

LEYDESDORFF, Loet; WAGNER, Caroline S. International collaboration in science and the formation of a core group. Journal of Infometrics, [s. I.], v. 2, n. 4, p. 317-325, out. 2008. http://dx.doi. org/10.1016/j.joi.2008.07.003. Disponível em: https://www.sciencedirect.com/science/article/abs/pii/ S1751157708000448?via\%3Dihub. Acesso em: 29 set. 2021.

LI, Ling-Li et al. Global stem cell research trend: bibliometric analysis as a tool for mapping of trends from 1991 to 2006. Scientometrics, Amsterdã, v. 80, n. 1, p. 39-58, 18 mar. 2009. DOI: http://dx.doi.org/10.1007/s11192008-1939-5. Disponível em: https://link.springer.com/article/10.1007\%2Fs11192-008-1939-5. Acesso em: 29 set. 2021.

LIMA, Maycke Young de. Coautoria na produção científica do PPGGeo/UFRGS: uma análise de redes sociais. Ciência da Informação, Brasília, v. 40, n. 1, p. 38-51, 2011. DOI: http://dx.doi.org/10.1590/s010019652011000100003. Disponível em: https://www.scielo.br/j/ci/a/wQMNJQWRxJBZwPCtttdXqDJ/?lang=pt. Acesso em: 29 set. 2021.

MACHADO, Raymundo das Neves. Produtividade científica brasileira na área de células-tronco (2001-2019). Revista Digital de Biblioteconomia e Ciência da Informação, Campinas, v. 19, p. e021003, 2021. DOI: http://dx.doi.org/10.20396/rdbci.v19i00.8662072. Disponível em: https://periodicos.sbu.unicamp.br/ojs/index. php/rdbci/article/view/8662072. Acesso em: 29 set. 2021.

MACHADO, Raymundo das Neves; VARGAS-QUESADA, Benjamín; LETA, Jacqueline. Intellectual structure in stem cell research: exploring Brazilian scientific articles from 2001 to 2010. Scientometrics, Amsterdã, v. 106, n. 2, p. 525-537, 2015. DOI: http://dx.doi.org/10.1007/s11192-015-1793-1. Disponível em: https://link.springer. com/article/10.1007\%2Fs11192-015-1793-1. Acesso em: 29 set. 2021.

MAIA, Maria Fatima; CAREGNATO, Sônia Elisa. Colaboração na produção científica em Ciências da Saúde: análise de cinco décadas de coautorias. In: ENCONTRO NACIONAL DE PESQUISAS EM CIÊNCIA DA INFORMAÇÃO, 12., 23-26 out. 2011, Brasília. Relatório G7, Produção e Comunicação da Informação em CT\&I. Brasília: XII ENANCIB, 2011. p. 2411-2416. Disponível em: http://200.20.0.78/repositorios/bitstream/ handle/123456789/2145/Colabora\%C3\%A7\%C3\%A30\%20-\%20Maia.pdf?sequence=1. Acesso em: 14 jan. 2020.

MANTEN, A. A. Publication of scientific information is not identical with communication. Scientometrics, Amsterdã, v. 2, n. 4, p. 303-308, 1980. DOI: http://dx.doi.org/10.1007/bf02016350. Disponível em: https://link. springer.com/article/10.1007\%2FBF02016350. Acesso em: 29 set. 2021.

MASON, Chris; DUNNILL, Peter. A brief definition of regenerative medicine. Regenerative Medicine, Londres, v. 3, n. 1, p. 1-5, 2007. DOI: http://dx.doi.org/10.2217/17460751.3.1.1. Disponível em: https://www. futuremedicine.com/doi/10.2217/17460751.3.1.1. Acesso em: 29 set. 2021.

MCMAHON, Dominique et al. Regenerative medicine in Brazil: small but innovative. Regenerative Medicine, Londres, v. 5, n. 6, p. 863-876, 2010. DOI: http://dx.doi.org/10.2217/rme.10.76. Disponível em: https://www. futuremedicine.com/doi/10.2217/rme.10.76. Acesso em: 29 set. 2021.

MEDINA-ARELLANO, María de Jesús. Contested secularity: governing stem cell science in Mexico. Science and Public Policy, Londres, v. 39, n. 3, p. 386-402, 2012. DOI: http://dx.doi.org/10.1093/scipol/scs028. Disponível em: https://academic.oup.com/spp/article-abstract/39/3/386/1726431?redirectedFrom=fulltext. Acesso em: 29 set. 2021. 
MEIRELLES, Lindolfo da Silva; CHAGASTELLES, Pedro Cesar; NARDI, Nance Beyer. Mesenchymal stem cells reside in virtually all post-natal organs and tissues. Journal of Cell Science, Londres, v. 119, n. 11, p. 2204-2213, 2006. DOI: http://dx.doi.org/10.1242/jcs.02932. Disponível em: https://journals.biologists.com/jcs/ article/119/11/2204/2956/Mesenchymal-stem-cells-reside-in-virtually-all. Acesso em: 29 set. 2021.

MENDEZ-OTERO, Rosalia; CARVALHO, Antonio Carlos Campos de. Global Update: Brazil. Regenerative Medicine, Londres, v. 7, n. 6, p. 144-147, 2012. DOI: http://dx.doi.org/10.2217/rme.12.84. Disponível em: https://www.futuremedicine.com/doi/10.2217/rme.12.84. Acesso em: 29 set. 2021.

MENEGHINI, Rogerio; PACKER, Abel L.; NASSI-CALÒ, Lilian. Articles by Latin American authors in prestigious journals have fewer citations. Plos One, São Francisco, v. 3, n. 11, p. e3804, 2008. DOI: http://dx.doi. org/10.1371/journal.pone.0003804. Disponível em: https://journals.plos.org/plosone/article?id=10.1371/journal. pone.0003804. Acesso em: 29 set. 2021.

MITTRA, James. The New Health Bioeconomy: R\&D policy and innovation for the twenty-first century. Basingstoke: Palgrave Macmill, 2016.

MORRISON, Michael. Promissory futures and possible pasts: the dynamics of contemporary expectations in regenerative medicine. BioSocieties, [s. I.], v. 7, n. 1, p. 3-22, 2012. DOI: http://dx.doi.org/10.1057/ biosoc.2011.24. Disponível em: https://link.springer.com/article/10.1057\%2Fbiosoc.2011.24. Acesso em: 29 set. 2021.

MUELLER, Suzana Pinheiro Machado. A publicação da ciência: áreas científicas e seus canais preferenciais. DataGramaZero - Revista de Ciência da Informação, João Pessoa, v. 6, n. 1, p. 2005.

PACKER, Abel Laerte. A eclosão dos periódicos do Brasil e cenários para o seu porvir. Educação e Pesquisa, São Paulo, v. 40, n. 2, p. 301-323, 2014. DOI: http://dx.doi.org/10.1590/s1517-97022014061860. Disponível em: https://www.scielo.br/j/ep/a/RGBqtc7ZPMRFJSYLB37SXTp/?lang=pt. Acesso em: 29 set. 2021.

PALMA, Verónica et al. Stem cell research in Latin America: update, challenges and opportunities in a priority research area. Regenerative Medicine, Londres, v. 10, n. 6, p. 785-798, 2015. DOI: http://dx.doi.org/10.2217/ rme.15.44. Disponível em: https://www.futuremedicine.com/doi/10.2217/rme.15.44. Acesso em: 29 set. 2021.

PERSSON, Olle; GLÄNZEL, Wolfgang; DANELL, Rickard. Inflationary bibliometric values: the role of scientific collaboration and the need for relative indicators in evaluative studies. Scientometrics, Amsterdã, v. 60, n. 3, p. 421-432, 2004. http://dx.doi.org/10.1023/b:scie.0000034384.35498.7d. Disponível em: https://link.springer. com/article/10.1023\%2FB\%3ASCIE.0000034384.35498.7d. Acesso em: 29 set. 2021.

PERSSON, Olle; GLÄNZEL, Wolfgang; DANELL, Jesús Pascual. A ciência nas regiões brasileiras: evolução da produção e das redes de colaboração científica. Transinformação, Campinas, v. 28, n. 1, p. 15-32, abr. 2016. DOI: http://dx.doi.org/10.1590/2318-08892016002800002. Disponível em: https://www.scielo.br/j/tinf/a/tv BDyptMBFSxRSt3VngySRC/?lang=pt. Acesso em: 29 set. 2021.

PRICE, Derek John de Solla. O desenvolvimento da ciência: análise histórica, filosófica, sociológica e econômica. Rio de Janeiro: Livros Técnicos e Científicos, 1976.

RABKIN, Y. M.; INHABER, H. Science on the periphery: a citation study of three less developed countries. Scientometrics, Amsterdã, v. 1, n. 3, p. 261-274, 1979. DOI: http://dx.doi.org/10.1007/bf02016310. Disponível em: https://link.springer.com/article/10.1007\%2FBF02016310. Acesso em: 29 set. 2021.

REZAIE, Rahim et al. Brazilian health biotech-fostering crosstalk between public and private sectors. Nature Biotechnology, Nova York, v. 26, n. 6, p. 627-644, 2008. DOI: http://dx.doi.org/10.1038/nbt0608-627. Disponível em: https://www.nature.com/articles/nbt0608-627. Acesso em: 29 set. 2021.

RIP, Arie; JOLY, Pierre-Benoit. Emerging spaces and governance: a position paper for EU-SPRI. a position paper for EU-SPRI. [S. I.: s. n.], 2012. Disponível em: https://www.researchgate.net/profile/Andy Stirling/publication/263962630_Emerging_Spaces_and_Governance_A_position_paper_for_EU-SPRI/ links/00b4953c67201913bd000000.pdf. Acesso em: 14 fev. 2020.

RODRIGUEZ-MEDINA, Leandro et al. International Ties at Peripheral Sites: co-producing social processes and scientific knowledge in Latin America. Science as Culture, Londres, v. 28, n. 4, p. 562-588, 2019. DOI: http:// dx.doi.org/10.1080/09505431.2019.1629409. Disponível em: https://www.tandfonline.com/doi/full/10.1080/0950 5431.2019.1629409. Acesso em: 29 set. 2021. 
ROHRA, Dileep K. Representation of less-developed countries in Pharmacology journals: an online survey of corresponding authors. BMC Medical Research Methodology, [s. I.], v. 11, n. 1, p. 1-8, 2011. DOI: http:// dx.doi.org/10.1186/1471-2288-11-60. Disponível em: https://bmcmedresmethodol.biomedcentral.com/articl es/10.1186/1471-2288-11-60. Acesso em: 29 set. 2021.

SALTER, Brian. Governing stem cell science in China and India: emerging economies and the global politics of innovation. New Genetics and Society, Basingstoke, v. 27, n. 2, p. 145-159, 2008. DOI: http://dx.doi.org/10.1080/14636770802077090. Disponível em: https://www.tandfonline.com/doi/ full/10.1080/14636770802077090. Acesso em: 29 set. 2021.

SANTIN, Dirce Maria; NUNEZ, Zizil Arledi Glienke; MOURA, Ana Maria Mielniczuk de. Produção científica brasileira sobre células-tronco de 2000 a 2013: características e colaboração internacional. Revista Eletrônica de Comunicação, Informação e Inovação em Saúde, Rio de Janeiro, v. 9, n. 2, p. 1-16, 2015. DOI: http://dx.doi.org/10.29397/reciis.v9i2.965. Disponível em: https://www.reciis.icict.fiocruz.br/index.php/ reciis/article/view/965/1937. Acesso em: 29 set. 2021.

SINGH, D. Publication bias - a reason for the decreased research output in developing countries. African Journal of Psychiatry, Cidade do Cabo, v. 9, n. 3, p. 153-155, 2006. DOI: http://dx.doi.org/10.4314/ajpsy. v9i3.30216. Disponível em: https://www.ajol.info//index.php/ajpsy/article/view/30216. Acesso em: 29 set. 2021.

SMITH, Elise; HUNT, Matthew; MASTER, Zubin. Authorship ethics in global health research partnerships between researchers from low or middle income countries and high income countries. BMC Medical Ethics, [s. I.], v. 15, n. 1, p. 1-8, 2014. DOI: http://dx.doi.org/10.1186/1472-6939-15-42. Disponível em: https:// bmcmedethics.biomedcentral.com/articles/10.1186/1472-6939-15-42. Acesso em: 29 set. 2021.

SONNENWALD, Diane H. Scientific collaboration. Annual Review of Information Science and Technology, White Plains, v. 41, n. 1, p. 643-681, 2007. DOI: http://dx.doi.org/10.1002/aris.2007.1440410121. Disponível em: https://asistdl.onlinelibrary.wiley.com/doi/10.1002/aris.2007.1440410121. Acesso em: 29 set. 2021.

SOUZA, André de Mello e (org.). Repensando a cooperação internacional para o desenvolvimento. Brasília, DF: Ipea, 2014.

SOUZA, Andréa Cerqueira. Periódicos científicos do Brasil e o dilema: publicar ou não em inglês? Scielo em Perspectiva, São Paulo, 1 set. 2017. Humanas. Disponível em: https://humanas.blog.scielo.org/ blog/2017/09/01/periodicos-cientificos-brasileiros-e-o-dilema-publicar-ou-nao-em-ingles/. Acesso em: 3 jan. 2021.

TARGINO, Maria das Graças; GARCIA, Joana Coeli Ribeiro. Ciência brasileira na base de dados do Institute for Scientific Information (ISI). Ciência da Informação, Brasília, DF, v. 29, n. 1, 2000. Disponível em: http:// revista.ibict.br/ciinf/article/view/904. Acesso em: 29 set. 2021.

VANZ, Samile Andrea de Souza; STUMPF, Ida Regina Chittó. Colaboração científica: revisão teóricoconceitual. Perspectivas em Ciência da Informação, Belo Horizonte, v. 15, n. 2, p. 42-55, 2010. DOI: http:/l dx.doi.org/10.1590/s1413-99362010000200004. Disponivel em: https://www.scielo.br/j/pci/a/Fz4q6DhPGhjnhx XmRxLw6Ct/?lang=pt. Acesso em: 29 set. 2021.

VELHO, Léa. Conceitos de Ciência e a Política Científica, Tecnológica e de Inovação. Sociologias, Porto Alegre, v. 13, n. 26, p. 128-153, 2011. DOI: http://dx.doi.org/10.1590/s1517-45222011000100006. Disponível em: https://www.scielo.br/j/soc/a/q5SC5wGHhpGpzL86NZyDgDS/?lang=pt. Acesso em: 29 set. 2021.

WASSERMAN, Stanley; FAUST, Katheryne. Social network analysis: methods and applications. Cambridge: Cambridge University Press, 1994.

WEBBER, Laura et al. High rates of obesity and non-communicable diseases predicted across Latin America. Plos One, São Francisco, v. 7, n. 8, p. e39589, 2012. DOI: http://dx.doi.org/10.1371/journal.pone.0039589. Disponível em: https://journals.plos.org/plosone/article?id=10.1371/journal.pone.0039589. Acesso em: 29 set. 2021.

WEBSTER, Andrew; HADDAD, Christian; WALDBY, Catherine. Experimental heterogeneity and standardisation: stem cell products and the clinical trial process. BioSocieties, [s. I.], v. 6, n. 4, p. 401-419, 2011. DOI: http://dx.doi.org/10.1057/biosoc.2011.17. Disponível em: https://link.springer.com/article/10.1057\%2 Fbiosoc.2011.17. Acesso em: 29 set. 2021.

WEBSTER, Andrew; WYATT, Sally (ed.). Health, Technology and Society: critical inquiries. Basingstoke: Palgrave Macmillan, 2020. 
WILSON-KOVACS, Dana M.; WEBER, Susanne; HAUSKELLER, Christine. Stem cells clinical trials for cardiac repair: regulation as practical accomplishment. Sociology of Health \& Illness, Boston, v. 32, n. 1, p. 89-105, jan. 2010. DOI: http://dx.doi.org/10.1111/j.1467-9566.2009.01191.x. Disponível em: https://onlinelibrary.wiley. com/doi/10.1111/j.1467-9566.2009.01191.x. Acesso em: 29 set. 2021.

ZBAR, Ariella; FRANK, Erica. Significance of Authorship Position: an open-ended international assessment. The American Journal of The Medical Sciences, [s. I.], v. 341, n. 2, p. 106-109, 2011. DOI: http://dx.doi. org/10.1097/maj.0b013e3181f683a1. Disponível em: https://www.amjmedsci.org/article/S0002-9629(15)313707/fulltext. Acesso em: 29 set. 2021.

ZHAO, Dangzhi; STROTMANN, Andreas. Intellectual structure of stem cell research: a comprehensive author co-citation analysis of a highly collaborative and multidisciplinary field. Scientometrics, Amsterdã, v. 87, n. 1, p. 115-131, 2010. DOI: http://dx.doi.org/10.1007/s11192-010-0317-2. Disponível em: https://link.springer.com/ar ticle/10.1007\%2Fs11192-010-0317-2. Acesso em: 29 set. 2021.

ZORZANELLI, Rafaela Teixeira et al. Pesquisa com células-tronco no Brasil: a produção de um novo campo científico. História, Ciências, Saúde-Manguinhos, Rio de Janeiro, v. 24, n. 1, p. 129-144, 2016. DOI: http:// dx.doi.org/10.1590/s0104-59702016005000026. Disponível em: https://www.scielo.br/j/hcsm/a/HpHtsFVjQLN8 RTVBFWzzZMh/?lang=pt. Acesso em: 29 set. 2021. 